\title{
Combined Hepatic and Inferior Vena Cava Resection for Colorectal Cancer
}

\author{
Jean-Sébastien Pelletier, Richdeep S. Gill* and David L. Bigam
}

Department of Surgery, University of Alberta, Edmonton, Alberta, Canada

\begin{abstract}
Hepatic metastases occur in up to half of all colorectal cancers, the third most common malignancy in the United States. Surgery provides the only chance for cure in this clinical situation and indications for resection are broadening. Colorectal metastases can invade the inferior vena cava, owing to its intimate association with the liver. While these lesions were historically classified as unresectable, surgical proficiency has progressed to the point that they can frequently be removed via a complex resection. Patient selection with the help of a multidisciplinary team and the careful use of pre-operative imaging studies is essential to maximize results. It is also critical that the operative surgeon is experienced with the complex anatomy, the resection techniques and the instruments available. While inferior vena cava invasion from colorectal cancer metastases is a poor prognostic factor, the evidence suggests that a combined hepatic and inferior vena cava resection can be performed with an acceptably low operative mortality and provides the best chance for long-term survival.
\end{abstract}

Keywords: Liver resection; Colorectal; Inferior vena cava; Cancer; Surgery

\section{Introduction}

Colorectal cancer is the third most common malignancy in the United States and the second leading cause of cancer-related death [1]. Additionally, 30-50\% of patients who develop colorectal cancer will develop metastases to their liver [2,3], which is more than any other distant site. Since first being reported in 1952 [4] surgical resection of metastatic disease has been offered and, with improvements in the understanding of hepatic anatomy as well as the development of safer surgical techniques, the perioperative mortality has become acceptably low.

Surgical resection is the only potentially curative treatment for most primary and secondary liver tumors [5]. In fact, survival with untreated colorectal liver metastases is usually less than a year [2]. While current chemotherapeutic regimens have extended median survival to greater than 20 months [6], large series have reported that the surgical resection of hepatic metastases has prolonged survival even further, with 5-year survival rates ranging from $21 \%$ to $58 \%[2,7]$ Impressively, 10-year survival can be expected in at least $1 / 6$ of these patients [2,8].

Unfortunately, surgery is not always feasible for patients with hepatic colorectal metastases. However, the proportion of patients with potentially resectable disease is increasing, which is at least partly due to improved colorectal cancer screening and post-operative surveillance. With improvements in chemotherapeutics, certain patients with unresectable or borderline resectable lesions are now being offered neoadjuvant chemotherapy, increasing the number of patients eligible for potential curative resections. Also, strategies such as staged resections, portal vein embolization and a combination of resection and ablative techniques have expanded indications for surgical treatment [2]. While it is acknowledged that large, bilobar and poorly located tumors have a worse prognosis, this burden of disease is no longer necessarily considered an absolute contraindications to resection [2].

Inferior vena cava (IVC) invasion occurs due to its intimate association with the liver. It has been estimated that as many as 3\% of hepatic lesions involve this structure [9], although there may only be a small proportion of these requiring an IVC resection [10]. Historically, these lesions were considered to be unresectable [11]. The first reported combined hepatic and IVC resection was done for a single patient in a series of right trisegmentectomies, but unfortunately this patient died 20 days post-operatively [12]. Two further, similar cases with better long-term outcomes were reported separately in 1988; one using a dacron graft and the other PTFE $[13,14]$. Since that time, there have been numerous series that have reported the success and technical feasibility of these combined resections [9,15-17].

\section{Risk Factors for Liver Resections}

Patient Risk Factors: As for any liver resection, patients must be chosen carefully to achieve optimal results and a multidisciplinary team is crucial in evaluating patients that are appropriate candidates for these operations. In order to be considered for such an extensive resection, the patient must not present with significant renal, hepatic or cardiopulmonary dysfunction and have a satisfactory performance status [18]. Additionally, at least 2 healthy, contiguous residual segments should remain, accounting for at least $20 \%$ of the preoperative functional liver [8].

Pre-operative imaging is necessary for all patients being considered for a hepatectomy. Imaging modalities include: triple-phase computed tomography (CT), magnetic resonance imaging (MRI), ultrasonography (US) and positron emission tomography (PET)-CT. Regardless of the chosen modality, evaluation of the hepatic vascular inflow and outflow, the biliary drainage as well as the future liver remnant is essential in determining resectability and for operative planning.

In order to pre-operatively determine whether there is in fact caval invasion, the clinician has the aforementioned imaging modalities at his disposal, as well as more invasive measures such as vena cavography. Intracaval endovascular ultrasonography has also been studied for this purpose and has promising results [19] but is limited by its availability and invasiveness. While certain imaging characteristics such as intracaval protruding lesions and a well developed collateral vasculature may increase the likelihood of invasion, none of these

*Corresponding author: Dr. Richdeep S. Gill, 9-50 Medical Sciences Building University of Alberta, Edmonton, Alberta, Canada, Tel:1-780-709-7473; Fax : 1-780-407-3283; E-mail: richdeep@ualberta.ca

Received November 28, 2011; Accepted December 06, 2011; Published December 12, 2011

Citation: Pelletier JS, Gill RS, Bigam DL (2011) Combined Hepatic and Inferior Vena Cava Resection for Colorectal Cancer. Surgery S4:001. doi:10.4172/21611076.S4-001

Copyright: (c) 2011 Gill RS, et al. This is an open-access article distributed under the terms of the Creative Commons Attribution License, which permits unrestricted use, distribution, and reproduction in any medium, provided the original author and source are credited. 
imaging modalities are conclusive and pre-operative assessment of IVC invasion remains difficult $[10,20]$. These investigations are limited by the IVC's thin wall and low pressure, which allows a hepatic lesion to easily compress it [21].

Procedural Risk Factors (Complex Anatomy, Vascular Reconstruction): The resection of any tumor that invades the IVC is inherently challenging and, as noted earlier, it is only recently that these resections have become feasible through increased operative experience, including liver transplantation $[9,22]$. It was previously believed that IVC invasion was a contraindication for resection, mainly because of the risk of massive hemorrhage and air embolism [5]. Many different techniques are now used to accomplish these procedures, including total vascular exclusion, venovenous bypass and hypothermic perfusion of the liver [5,23-25].

Total hepatic vascular exclusion, while having the benefit of minimizing blood loss, must be balanced against rendering the hepatic remnant ischemic and compromising post-operative hepatic recovery. While a normal liver may tolerate up to 90 minutes of ischemia, in a pathologic liver, it is accepted that it may only tolerate 60 minutes. Veno-veno bypass may be utilized for hemodynamic instability following IVC clamping [11] while hypothermic perfusion has the benefit of increasing the liver's tolerance to ischemia [9].

IVCrepair maybe accomplished using different methods, depending on the extent of the defect as well as surgeon preference. These methods include direct primary repair, a patch repair (autologous vein, bovine pericardium or Gore-Tex) for larger defect or, for extensively involved lesions, graft replacement (ringed PTFE). The entire IVC should be replaced with a graft prosthesis if $>50 \%$ of the IVC is involved, if there is longitudinal involvement or if there is an intracaval thrombus [9]. If possible, it is preferable to perform a primary or a patch repair, as these are safer and easier to perform, unless it is excessively narrowed [18].

Exclusion criteria for this procedure include hepatic, cardiovascular or renal failure, portal hypertension, or an inability to obtain an R0 resection or an acceptable future liver remnant. $[8,18]$ The presence of extra-hepatic disease has been considered a contraindication [9], however, in select cases may be considered for resection, especially if they respond favorably to systemic therapy [8].

\section{Surgical Procedure}

The description of hepatic resections dates back to the turn of the century [26] and continued through the early twentieth century [4,27]. It wasn't until Couinaud, through his work with liver casts, described the liver as eight functional units [28] that a better understanding of intra-hepatic anatomy was achieved. This knowledge is necessary for any liver surgery, especially when a major hepatic resection with a potential vascular reconstruction is planned.

The use of intra-operative ultrasound has become an invaluable tool for hepatic surgeons. It allows for a real-time analysis of the tumor burden prior to parenchymal transection, as well as an evaluation of the proximity of major vascular structures. In the case of major vascular invasion, it has the added advantage of confirming portal vein and hepatic artery inflow as well as hepatic vein outflow of the hepatic remnant to ensure respectability [18]. Different techniques are now utilized to transect the hepatic parenchyma safely, which include snap fracture, ultrasonic dissectors and hydro dissectors to name a few.

At surgical exploration, the surgeon must assess whether the lesion is in fact invading the IVC, or if it is merely close or adherent. If an IVC resection is required, total hepatic exclusion, which involves the clamping of the supra-hepatic IVC, the infra-hepatic IVC and the portal triad, may be performed. Veno-venous bypass can be performed for hemodynamic instability following the clamping of the IVC. Ex situ resections have also been described for these lesions and is preferred by some surgeons.[29] The advantages of the ex situ procedure include isolated hypothermic resection under the protective effects of liver perfusion and increased time to perform complex vascular anastomoses. This is balanced against the disadvantages of an increased number of anastamoses, longer operative times and higher mortality and liver failure rates [11,29].

\section{Results}

A definitive evaluation of the outcomes of these procedures is difficult, owing to the fact that this is a relatively rare procedure, even in high-volume centers. As such, these studies include a small amount of patients and are at higher risk for bias.

In spite of the complexity of these surgical procedures, the perioperative mortality rates in published reports have remained relatively low, even in earlier series. Most series report this as being less than $10 \%,[5,9,16-18,30]$ but it is also noted that these kind of results can only be achieved through careful patient selection [9].

Major morbidity rates from documented series range from 25$64 \%[5,9,11,16,18]$. The rates of surgery-specific morbidities were reported in multiple studies. Graft occlusion, which can be due to thrombus, tumor recurrence or a regenerating liver, was noted to be present from $0-19 \%[9,11,18,23,31]$ although the methods used for the detection of this complication were heterogeneous. Graft infection was inconsistently reported, but appears to be a rare complication. Only one documented graft infection was found in a series of 29 patients [18] while others reported that it wasn't seen at all [31].

Fulminant hepatic failure post liver resection was uncommon, ranging from $0-6 \%[9,16,18]$ but a transient hepatic dysfunction was more commonly encountered, with rates ranging from $16-32 \%$ $[5,9,23,31]$.

Recurrence of disease was, not surprisingly, relatively common considering the advanced stage of disease. While the rates varied widely, ranging from $17-91 \%[16,17,23,31]$, though most series looking specifically at colorectal metastases were quite small. For series whose follow-up was sufficiently long to report it, the five-year overall survival rates ranged from 19.6 to $51.9 \%[9,15,16]$.

\section{Conclusion}

Surgical resection is the only evidence -based treatment strategy for long-term survival for colorectal liver metastases. When these lesions invade the IVC, while more technically challenging, this still holds true. Although the body of literature on this subject is relatively small, with improving and evolving surgical expertise and associated acceptably low surgical mortality, surgical resection should be considered for any patient with this clinical presentation.

\section{References}

1. Amersi F, Agustin M, Ko CY (2005) Colorectal cancer: Epidemiology, risk factors, and health services. Clin colon rectal surg 18: 133-140.

2. Adam R, Hoti E, Bredt LC (2010) Evolution of neoadjuvant therapy for extended hepatic metastases--have we reached our (non-resectable) limit? J Surg Oncol 102: 922-931.

3. D'Angelica M, Kornprat P, Gonen M, DeMatteo RP, Fong Y, et al. (2011) Effect on outcome of recurrence patterns after hepatectomy for colorectal metastases. Ann Surg Oncol. 18: 1096-1103.

4. Lortat-Jacob JL, Robert HG, Henry C (1952) Excision of the right lobe of the 
Citation: Gill RS, Pelletier JS, Bigam DL (2011) Combined Hepatic and Inferior Vena Cava Resection for Colorectal Cancer. Surgery S4:001. doi:10.4172/2161-1076.S4-001

liver for a malignant secondary tumor. Arch Mal Appar Dig Mal Nutr 41: 662667.

5. Azoulay D, Andreani P, Maggi U, Salloum C, Perdigao F, et al. (2006) Combined liver resection and reconstruction of the supra-renal vena cava: The Paul Brousse experience. Ann Surg 244: 80-88.

6. Chua TC, Saxena A, Chu F, Zhao J, Morris DL (2011) Predictors of cure after hepatic resection of colorectal liver metastases: An analysis of actual 5- and 10-year survivors. J Surg Oncol 103: 796-800.

7. Chua TC, Liauw W, Koong HN, Esquivel J (2011) Surgical therapies in metastatic colorectal cancer with a potential for cure. Am J Clin Oncol 34: 326331

8. Brown RE, Bower MR, Martin RC (2010) Hepatic resection for colorectal liver metastases. Surg Clin North Am 90: 839-852.

9. Nardo B, Ercolani G, Montalti R, Bertelli R, Gardini A, et al. (2005) Hepatic resection for primary or secondary malignancies with involvement of the inferior vena cava: Is this operation safe or hazardous?. J Am Coll Surg. 201: 671-679.

10. Hashimoto T, Minagawa M, Aoki T, Hasegawa K, Sano K et al. (2008) Cava invasion by liver tumor is limited. J Am Coll Surg 207: 383-392.

11. Sarmiento JM, Bower TC, Cherry KJ, Farnell MB, Nagorney DM (2003) Is combined partial hepatectomy with segmental resection of inferior vena cava justified for malignancy?. Arch Surg 138: 624-630.

12. Starzl TE, Koep LJ, Weil R, Lilly JR, Putnam CW, et al. (1980) Right trisegmentectomy for hepatic neoplasms. Surg Gynecol Obstet 150: 208-214.

13. Iwatsuki S, Todo S, Starzl TE (1988) Right trisegmentectomy with a synthetic vena cava graft. Arch Surg 123: 1021-1022.

14. Kumada K, Shimahara Y, Fukui K, Itoh K, Morikawa S, et al. (1988) Extended right hepatic lobectomy: Combined resection of inferior vena cava and its reconstruction by EPTFE graft (gore-tex). case report. Acta Chir Scand 154 481-483.

15. Malde DJ, Khan A, Prasad KR, Toogood GJ, Lodge JP (2011) Inferior vena cava resection with hepatectomy: Challenging but justified. Hpb 13: 802-810.

16. Miyazaki M, Ito H, Nakagawa K, Ambiru S, Shimizu H, et al. (1999) Aggressive surgical resection for hepatic metastases involving the inferior vena cava. Am J Surg 177: 294-298

17. Johnson ST, Blitz M, Kneteman N, Bigam D (2006) Combined hepatic and inferior vena cava resection for colorectal metastases. J Gastrointest Surg 10: 220-226.

18. Bower TC, Nagorney DM, Cherry KJ Jr, Toomey BJ, Hallett JW, et al. (2000) Replacement of the inferior vena cava for malignancy: An update. J Vasc Surg 31: $270-281$.
19. Kaneko T, Nakao A, Nomoto S, Endo T, Itoh S, et al. (1996) Intracaval endovascular ultrasonography for preoperative assessment of retrohepatic inferior vena cava infiltration by malignant hepatic tumors. Hepatology 24 1121-1127.

20. Okada $Y$, Nagino M, Kamiya J, Yamamoto $H$, Hayakawa $N$, et al. (2003) Diagnosis and treatment of inferior vena caval invasion by hepatic cancer. World J Surg 27: 689-694.

21. Maeba T, Okano K, Mori S, Karasawa Y, Goda F, et al. (2000) Extent of pathologic invasion of the inferior vena cava in resected liver cancer compared with possible caval invasion diagnosed by preoperative images. J Hepatobiliary Pancreat Surg 7: 299-305.

22. Hemming AW, Reed AI, Langham MR Jr, Fujita S, Howard RJ (2004) Combined resection of the liver and inferior vena cava for hepatic malignancy. Ann Surg 239: 712-719.

23. Lodge JP, Ammori BJ, Prasad KR, Bellamy MC (2000) Ex vivo and in situ resection of inferior vena cava with hepatectomy for colorectal metastases. Ann Surg 231: 471-479.

24. Kim YI, Hiratsuka K, Kitano S, Joo DH, Kamada N, et al. (1996) Simple in situ hypothermia reduced ischaemic injury to human liver during hepatectomy. Eur J Surg 162: 717-721.

25. Ohwada S, Ogawa T, Kawashima Y, Ohya T, Kobayashi I, et al. (1999) Concomitant major hepatectomy and inferior vena cava reconstruction. J Am Coll Surg 188: 63-71.

26. Keen WW (1899) Report of a case of resection of the liver for the removal of a neoplasm, with a table of seventy-six cases of resection of the liver for hepatic tumors. Ann Surg 30: 267-283.

27. Turner GG (1923) a case in which an adenoma weighing $2 \mathrm{lb} .3 \mathrm{oz}$. was successfully removed from the liver: With remarks on the subject of partial hepatectomy. Proc R Soc Med 16: 43-56.

28. Couinaud C (1954) Lobes et segments hepatiques: notes sur l'architecture anatomiqueet chirurgicale de foie. Presse Med 62: 709-712.

29. Oldhafer KJ, Lang H, Schlitt HJ, Hauss J, Raab R, et al. (2000) Long-term experience after ex situ liver surgery. Surgery 127: 520-527.

30. Arii S, Teramoto K, Kawamura T, Takamatsu S, Sato E, et al. (2003) Significance of hepatic resection combined with inferior vena cava resection and its reconstruction with expanded polytetrafluoroethylene for treatment of liver tumors. J Am Coll Surg 196: 243-249.

31. Delis SG, Madariaga J, Ciancio G (2007) Combined liver and inferior vena cava resection for hepatic malignancy. J Surg Oncol 96: 258-264.
This article was originally published in a special issue, Complex Gastrointestinal Surgery and its Risk Factors handled by Editor(s). Dr. Shahzeer karmali, University of Alberta, USA 